\title{
Thoracic endometriosis
}

\section{Yen-Sung Lin MD, Chih-Yen Tu MD}

Competing interests: None declared.

This article has been peer reviewed.

\section{Affiliations: From the} Division of Pulmonary and Critical Care Medicine (Lin, $\mathrm{Tu}$ ), Department of Internal Medicine, China Medical University Hospital; and the Department of Life Sciences (Tu), National Chung Hsing University, Taiwan, China

\section{Correspondence to:} Dr. Chih-Yen Tu, chesttu@gmail.com

CMAJ 2011. DOI:10.1503 /cmaj.100804

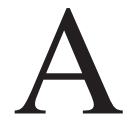
44-year-old woman presented to hospital with a 10-day history of hemoptysis. Her medical history included endometriosis and an ovarian cystectomy six years previously. Her hemoptysis coincided with her current menstrual period. She had no history of weight or appetite change, and was a nonsmoker. She was afebrile, with a normal blood leukocyte count. Chest radiography showed two nodules in the right lower lobe (Figure 1), and computed tomography of the chest showed multiple cavitary nodules bilaterally with a left-sided pneumothorax (Appendix 1, available at www.cmaj.ca/lookup/suppl /doi:10.1503/cmaj.100804/-/DC1). Although it is rare, we suspected thoracic endometriosis based on the patient's history and clinical presentation, but we could not exclude malignancy or granulomatous disease. We decided to proceed with video-assisted thoracoscopic surgery (VATS) to obtain tissue for pathologic

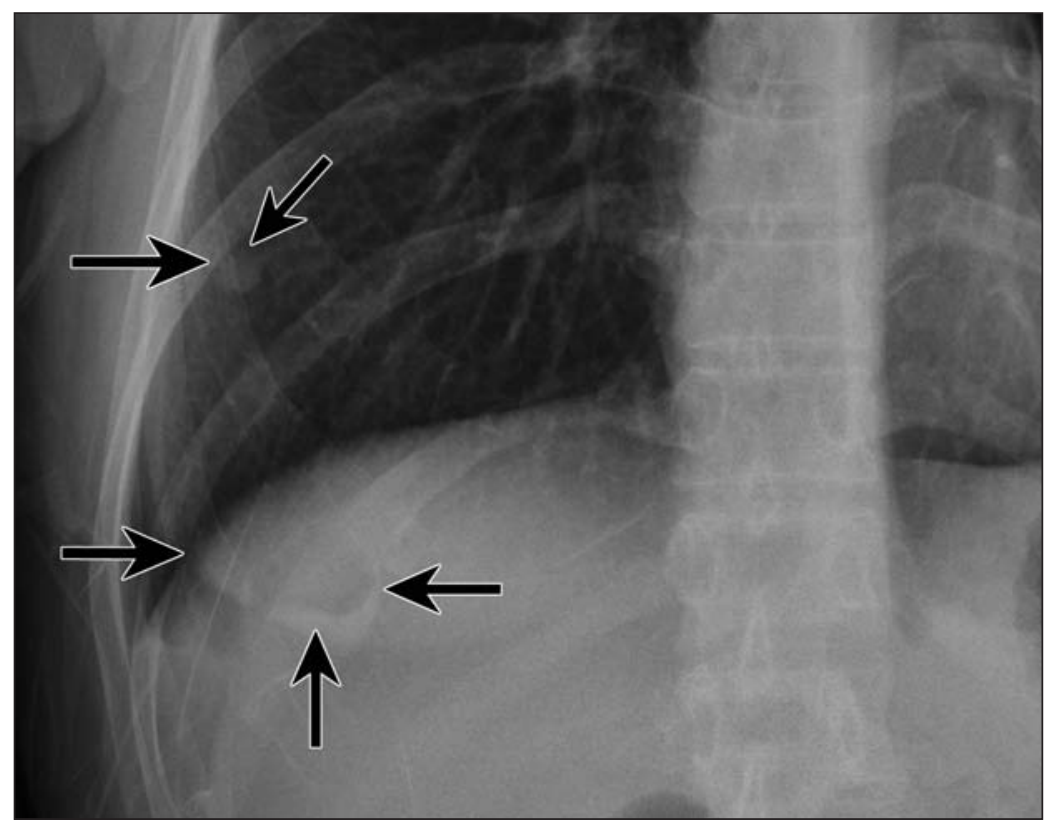

Figure 1: Chest radiograph (cropped) of a 44-year-old woman with hemoptysis showing two nodules (arrows) over the right lung. examination. We removed a nodule from the left lung, and pathologic examination showed abundant endometrial glands and stroma (Appendix 2, available at www.cmaj.ca /lookup/suppl/doi:10.1503/cmaj.100804/-/DC1), consistent with thoracic endometriosis. The patient declined hormonal therapy because of concerns about long-term adverse effects. Three months later, we resected several nodules from her right lung. The patient's postoperative course was uneventful, and she remained free of hemoptysis during five months of follow-up.

Thoracic endometriosis may involve the trachea, bronchi, lung parenchyma, pleura or diaphragm. The presentation typically includes pneumothorax, hemoptysis, a lung mass or a combination of the above. Most instances occur in the third and fourth decades of life, and the right hemithorax is more often affected than the left side. ${ }^{1}$ Chest radiography is often normal but may show solitary or multiple pulmonary nodules, which change in size during the menstrual cycle. Computed tomography is more sensitive than plain radiography for diagnosis of pulmonary endometriosis. ${ }^{2}$ The treatment of pulmonary endometriosis may be medical or surgical. Although medical treatment involving gonadotropin-releasing hormone agonists has been recommended as the first line in treatment of extrapelvic endometriosis, ${ }^{3}$ preliminary evidence based on small case series suggests that lung resection using VATS for periodic hemoptysis occurring at the time of menstruation can also be effective. ${ }^{4,5}$

\section{References}

1. Carter EJ, Ettensohn DB. Catamenial pneumothorax. Chest 1990;98:713-6.

2. Ciudad MJ, Santamaría N, Bustos A, et al. Imaging findings in catamenial pneumothorax. Radiologia 2007;49:263-7.

3. Practice Bulletin No. 114: management of endometriosis. Obstet Gynecol 2010;116:223-36.

4. Inoue T, Kurokawa Y, Kaiwa Y, et al. Video-assisted thoracoscopic surgery for catamenial hemoptysis. Chest 2001;120: 655-8.

5. Kim CJ, Nam HS, Lee CY, et al. Catamenial hemoptysis: a nationwide analysis in Korea. Respiration 2010;79:296-301. 